\title{
Anomalous energy yields in thermodynamic calculations: importance of accounting for pH-dependent organic acid speciation
}

\author{
Jan Dolfing, Aiping Xu and Ian M Head
}

The ISME Journal (2010) 4, 463-464; doi:10.1038/ismej.2010.14; published online 18 February 2010

\section{Introduction}

Methanogenic ecosystems function close to oxidationreduction equilibrium with change in Gibbs free energy $(\Delta G)$ values in the range of -10 to $-20 \mathrm{~kJ} \mathrm{~mol}^{-1}$ (Hoehler et al., 1998; Jackson and McInerney, 2002). With such small margins, attention to detail when making free energy calculations becomes exceedingly important. A pervasive source of confusion, if not error, when making free energy calculations is the fact that organic acids and their anions occur simultaneously (Mazur et al., 2003; Mun et al., 2008). Here, we point out that such confusion is not necessary, as weak acids and their conjugated bases are in thermodynamic equilibrium in anaerobic ecosystems. This equilibrium implies that Gibbs free energy values for redox reactions are to be calculated by $G_{\mathrm{f}}$ values of either the acid, with the formula $G_{\mathrm{f}}=G_{\mathrm{f}}^{\mathrm{o}}+R T \ln \alpha$, or the conjugated base with the formula $G_{\mathrm{f}}=G_{\mathrm{f}}^{\mathrm{o}}+R T \ln (1-\alpha)$, where $\alpha=10^{-\mathrm{pH}} /\left(10^{-\mathrm{pH}}+10^{-\mathrm{pK})}\right.$; by incorporating either the acid or its conjugated base the counterpart is incorporated implicitly.

\section{Energetic implications}

Thermodynamic equilibrium between weak acids and their conjugated bases implies that $\Delta G$ values are $(R T \ln 10)\left(\log \alpha-(1-\alpha) \mathrm{p} K_{\mathrm{a}}+(1-\alpha) \mathrm{pH}\right) \mathrm{kJ}$ different from a situation where simultaneous occurrence of both species would not occur. Conceptually, this can easily be appreciated. For example, at $\mathrm{pH}=\mathrm{p} K_{\mathrm{a}}$ in a nominally $1 \mathrm{mM}$ solution of acetic acid, $0.5 \mathrm{mM}$ occurs as acetate and $0.5 \mathrm{mM}$ as acetic acid. Thus, acetoclastic methanogens experience an acetic acid potential corresponding to $0.5 \mathrm{mM}$ rather than to the $1 \mathrm{mM}$ that would be expected if dissociation of acetate did not occur. This dissociation effect is maximal when the $\mathrm{pH}$ is equal to the $\mathrm{p} K_{\mathrm{a}}$ value of a reactant or a product

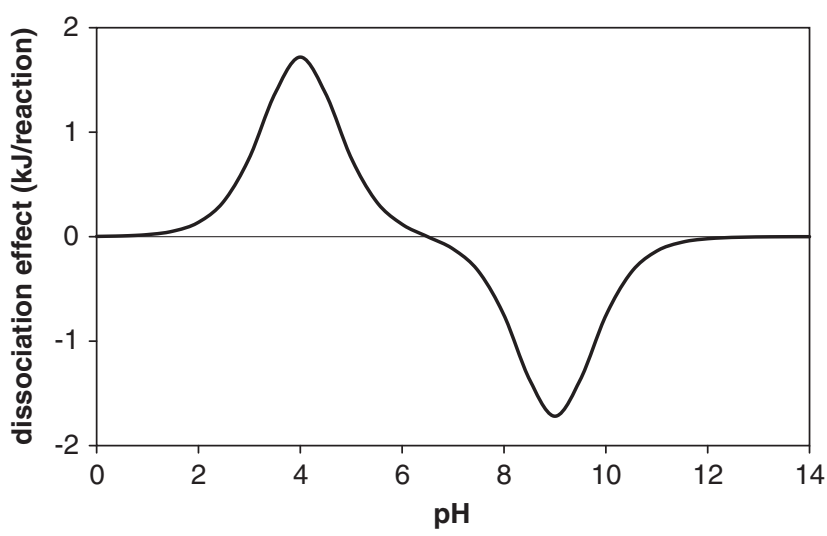

Figure 1 Dissociation of weak acids affects the energy yield of microbial reactions in anaerobic ecosystems. For a reaction $\mathrm{AH}+\mathrm{B} \rightarrow \mathrm{CH}+\mathrm{D}$ with $\mathrm{p} K_{\mathrm{a}}(\mathrm{AH})=4$ and $\mathrm{p} K_{\mathrm{a}}(\mathrm{CH})=9$, the effect is maximal at $\mathrm{pH}$ values of 4 and 9 ; at $\mathrm{pH}=4$ dissociation has a positive effect on $\Delta G$ and hence a negative effect on the energy available to the microbes, whereas at $\mathrm{pH}=9$ the effect is the opposite. The curve is based on the formula $\Delta G=(-R T \ln 10)$

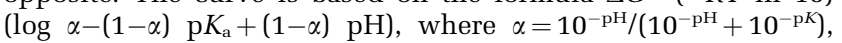
$R=8.3145 \mathrm{~J} \mathrm{~mol}^{-1} \mathrm{~K}^{-1}$, and $T$ is temperature in $\mathrm{K}$.

(Figure 1). Thermodynamic equilibrium between weak acids and their conjugated bases also implies that in a given environment $\Delta G$ for, for example, the reaction $\mathrm{CH}_{3} \mathrm{COOH} \rightarrow \mathrm{CO}_{2}+\mathrm{CH}_{4}$ is identical to $\Delta G$ for the reaction $\mathrm{CH}_{3} \mathrm{COO}^{-}+\mathrm{H}^{+} \rightarrow \mathrm{CO}_{2}+\mathrm{CH}_{4}$ in that environment.

\section{Implications for $\Delta G$ calculations}

The error made by neglecting speciation is relatively minor as long as the proper (that is, the dominant) species is used for $\Delta G$ calculations. Speciation of a weak acid is thermodynamically most significant at $\mathrm{pH}$ values close to its $\mathrm{p} K_{\mathrm{a}}$ value. The maximum error of neglecting speciation is $R T \ln 0.5$, at $25^{\circ} \mathrm{C}$, that is $1.72 \mathrm{~kJ} \mathrm{~mol}^{-1}$. Given the low amounts of energy at which many anaerobic ecosystems function values of that order of magnitude are not necessarily negligible.

Figure 2 illustrates the effect of $\mathrm{pH}$ on the energetics of methanogenesis from acetic acid/ 


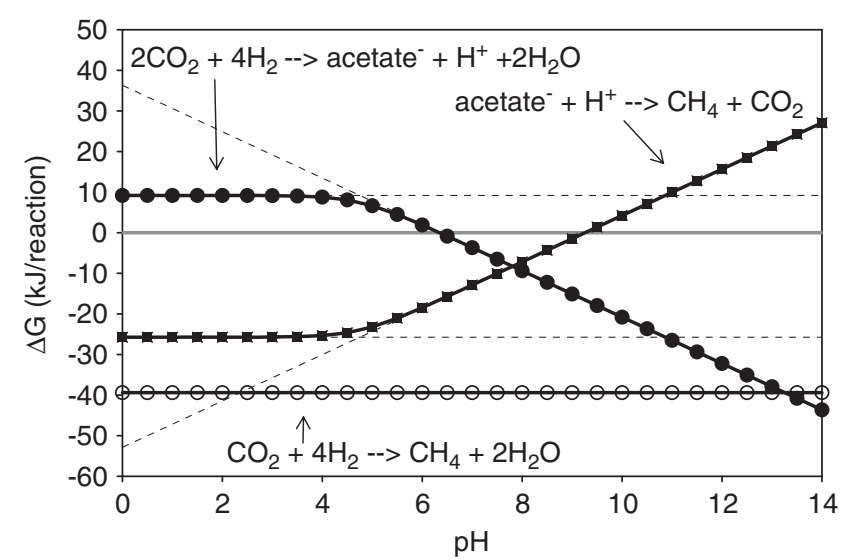

Figure 2 Effect of $\mathrm{pH}$ on $\Delta G$ values for methanogenesis from acetic acid/acetate (filled squares), for methanogenesis from $\mathrm{H}_{2}+\mathrm{CO}_{2}$ (open circles) and for acetogenesis from $\mathrm{H}_{2}+\mathrm{CO}_{2}$ (closed circles) at low concentrations of $\mathrm{H}_{2}(10 \mathrm{~Pa})$ and acetic acid/acetate $(100 \mu \mathrm{M})$ under otherwise standard conditions $\left(\mathrm{CO}_{2}\right.$ and $\mathrm{CH}_{4}$ at $1 \mathrm{~atm} ; \mathrm{T}=25^{\circ} \mathrm{C}$ ).

acetate and from $\mathrm{H}_{2}+\mathrm{CO}_{2}$, and on the energetics of acetogenesis from $\mathrm{H}_{2}+\mathrm{CO}_{2}$ at low concentrations of $\mathrm{H}_{2} \quad(10 \mathrm{~Pa})$ and acetic acid/acetate $(100 \mu \mathrm{M})$. At constant partial pressures of $\mathrm{CO}_{2}$ and $\mathrm{CH}_{4} \Delta G$ for methanogenesis from $\mathrm{H}_{2}+\mathrm{CO}_{2}$ is independent of $\mathrm{pH}$. Production or consumption of acetic acid/acetate changes this pattern. At $\mathrm{pH}$ values below the $\mathrm{p} K_{\mathrm{a}}$ for acetic acid, $\Delta G$ values for $\mathrm{H}_{2}$-based acetogenesis and acetoclastic methanogenesis are essentially independent of $\mathrm{pH}$, while at $\mathrm{pH}$ values above this $\mathrm{p} K_{\mathrm{a}}$ these $\Delta G$ values are a linear function of $\mathrm{pH}$.

\section{Acknowledgements}

We acknowledge funding from the European Commission, which supported this work through ECOSERV, a Marie Curie Excellence Grant (EXT 023469) and from EPSRC (Grant no. EP/E057462/1).

$J$ Dolfing is at School of Civil Engineering and Geosciences, Newcastle University, Newcastle upon Tyne, England, UK;

$\mathrm{AXu}$ is at School of Chemical Engineering and Advanced Materials, Newcastle University, Newcastle upon Tyne, England, UK and IM Head is at School of Civil Engineering and Geosciences, Newcastle University, Newcastle upon Tyne, England, UK

\section{References}

Hoehler TM, Alperin MJ, Albert DB, Martens CS. (1998). Thermodynamic control on hydrogen concentrations in anoxic sediments. Geochim Cosmochim Acta 62: 1745-1756.

Jackson BE, McInerney MJ. (2002). Anaerobic microbial metabolism can proceed close to thermodynamic limits. Nature 415: 454-456.

Mazur CS, Jones WJ, Tebes-Stevens C. (2003). $\mathrm{H}_{2}$ consumption during the microbial reductive dehalogenation of chlorinated phenols and tetrachloroethene. Biodegradation 14: 285-295.

Mun CH, Ng WJ, He J. (2008). Acidogenic sequencing batch reactor start-up procedures for induction of 2,4,6-trichlorophenol dechlorination. Water Res 42: 1675-1683. 